\title{
Clinicoetiological Pattern and Outcome of Neonates Requiring Mechanical Ventilation: Study in a Tertiary Care Centre
}

\author{
Mohini Yadav, Gauri Chauhan, A. K. Bhardwaj, P. D. Sharma \\ Department of Pediatrics, M.M. Institute of Medical Sciences and Research, Ambala, Haryana, India
}

\section{Abstract}

\begin{abstract}
The clinical and etiological pattern of ventilated newborns, their outcome in relation to morbidity and mortality was studied with 50 ventilated newborns, including outborns. M:f ratio was 2.1:1. The most common gestational age 28-36 weeks $(60 \%)$ and mostly were appropriate for gestational age (66\%). Survival rate 40\% (20/50) being directly proportional to the gestational age and intrauterine growth pattern $(P<0.01)$. Babies by LSCS Lower Segment Cessarian Section survived more than born by normal vaginal delivery (46.7\% vs. 37.1\%). More outborn survival could be related to their advanced gestational age on presentation. The initial assessment of APGAR score of $>7$ had a better outcome $(56.3 \% ; P<0.03)$. The most common indication of ventilation was hyaline membrane disease $(19 / 50)$ but the survival rate best in babies with meconium aspiration syndrome (54.5\%). The most prevalent complication was sepsis (survival rate $60 \%$ ) while conditions such as shock, intraventricular hemorrhage, disseminated intravascular coagulation, air leak syndrome, and pulmonary hemorrhage had $100 \%$ mortality. Thus, the outcome as survival is constrained by many factors; newborn's profile, conditions at birth, and postnatal resuscitation.
\end{abstract}

Keywords: APGAR, hyaline membrane disease, mechanical ventilation, meconium aspiration syndrome, sepsis

\section{INTRODUCTION}

Mechanical ventilation for critically ill newborn with intermittent positive or negative pressure was introduced in 1960s. This study was done in a tertiary care neonatal unit to assess the common indications of ventilation course during ventilation and to evaluate the final outcome as measured by survival of ventilated babies.

\section{Case Report}

This is a prospective study done in our institute, M.M. Institute of Medical Sciences and Research, on newborns admitted to neonatal intensive care unit; inborn and outborn neonates both were included in this study. All enrolled neonates were carefully examined and detailed antenatal, natal, and postnatal history was obtained from mothers after informed consent from both the parents. Fifty neonates were included over a period of 2 years (October 2013-September 2014); neonates who died within $2 \mathrm{~h}$ of admission and who left against medical advice were excluded from the study. The details of mode of delivery, indication for intervention, APGAR score, and resuscitation, if done were recorded. The initial objective

\begin{tabular}{|l|l|}
\hline \multicolumn{3}{|c|}{ Access this article online } \\
\hline Quick Response Code: & Website: \\
\hline & www.ijccm.org \\
\hline & \\
\hline
\end{tabular}

assessment of respiratory distress was made using Downe's respiratory distress score ${ }^{[1]}$ which was compared and found to correspond to blood gas values before subjecting the neonate for assisted ventilation.

Appropriate data entry and statistical analysis were performed on Microsoft Excel and SPSS Statistical Software (2015). Continuous variables were presented as mean and standard deviation while categorical variables as number and percentage. Ninety-five percent confidence interval was estimated for various point estimates. Chi-square test was used to compare the association among two or more categorical variables. All statistical tests were two-tailed, and alpha level of significance was set $<5 \%$. $P<0.05$ was taken as statistically significant.

Out of the enrolled neonates, 32 were inborn and 18 were outborn. The number of neonates who survived were 20 while 30 of the total expired. The general profile and

Address for correspondence: Dr. Gauri Chauhan, B-24, MMU Complex, Mullana, Ambala - 133 207, Haryana, India. E-mail: pgfinalgauri@gmail.Com

This is an open access journal, and articles are distributed under the terms of the Creative Commons Attribution-NonCommercial-ShareAlike 4.0 License, which allows others to remix, tweak, and build upon the work non-commercially, as long as appropriate credit is given and the new creations are licensed under the identical terms.

For reprints contact: reprints@medknow.com

How to cite this article: Yadav M, Chauhan G, Bhardwaj AK, Sharma PD. Clinicoetiological pattern and outcome of neonates requiring mechanical ventilation: Study in a tertiary care center. Indian J Crit Care Med 2018;22:361-3. 
indication of ventilation of the enrolled neonates $(n=50)$ are depicted in Figure 1. The male:female ratio was 2.1:1 and gestational age of most of the ventilated babies was between 28 and 36 weeks, but the intrauterine growth pattern of most of the babies was appropriate for gestational age (AGA) $(33 / 50 ; 66 \%)$. The survival rate of the neonates was directly proportional to their gestational age and their intrauterine growth pattern [Table 1]. The mean gestational age of the survivors was $34.6 \pm 3.38$ weeks to $33.4 \pm 4.5$ weeks of nonsurvivors which was statistically significant $(P<0.01)$ and babies who were AGA survived more (54.5\%) which was statistically significant parameter $(P<0.01)$. The APGAR score of $>7$ in the newborns showed a high percentage of survival, $56.3 \%(P<0.03)$ compared to those with APGAR of $<7$ at birth.

\begin{tabular}{lccc}
\hline Table 1: Profile of survivors and non survivors & \\
\hline Parameters & $\begin{array}{c}\text { Mean in } \\
\text { survivors }\end{array}$ & $\begin{array}{c}\text { Mean in non } \\
\text { survivors }\end{array}$ & $\boldsymbol{P}$ \\
\hline Gestational age (in weeks) & $34.6 \pm 3.38$ & $33.4 \pm 4.5$ & $<0.01$ \\
Birth weight (in grams) & $2173 \pm 665$ & $1611 \pm 791$ & 0.15 \\
Duration of ventilation (in hours) & $91.6 \pm 61.2$ & $71.3 \pm 55.5$ & 0.33 \\
Duration of hospital stay (in hours) & $373.1 \pm 280.8$ & $124.5 \pm 100.6$ & 0.02 \\
\hline
\end{tabular}

The most common indication of ventilation was hyaline membrane disease (HMD) followed by sepsis and perinatal asphyxia, but the significant survival rate was found in babies with perinatal asphyxia being ventilated $(P=0.03)$. The complications encountered were sepsis, ventilator-associated pneumonia (VAP), persistent pulmonary hypertension of the newborn (PPHN), intraventricular hemorrhage (IVH), shock, bronchopulmonary dysplasia (BPD), disseminated intravascular coagulation, air leak syndrome, and pulmonary hemorrhage. Of this sepsis was the most common complication followed by pneumonia, PPHN/shock, IVH [Table 2]. Although none of these variables were identified to be an independent predictor of mortality. The duration of ventilation of the survivors and nonsurvivors showed no statistical difference, but the duration of hospital stay was more in survivors $373.1 \pm 280.8 \mathrm{~h}$ to $124.5 \pm 100.6 \mathrm{~h}$ in nonsurvivors $(P=0.02)$.

\section{Discussion}

The most common indication of ventilation in our study was HMD (38\%), but the survival rate of same was quite low $(31.6 \%)$. Dutt et al. ${ }^{[2]}$ found it as the third-most common (18.98\%) while Mathur et al. ${ }^{[3]}$ as fourth-most common cause $(8.4 \%)$ of ventilation. Although they reported a better

Table 2: Analysis of survival in relation to complications

\begin{tabular}{|c|c|c|c|c|}
\hline Complication & $\begin{array}{l}\text { No. of babies with } \\
\text { complication }\end{array}$ & $\begin{array}{c}\text { No. of babies with } \\
\text { complications that survived }\end{array}$ & $\begin{array}{l}\% \text { survival of babies } \\
\text { with complications }\end{array}$ & $P$ \\
\hline Sepsis & 10 & 06 & $60 \%$ & 0.14 \\
\hline VAP* & 04 & 03 & $75 \%$ & 0.29 \\
\hline PPHN* & 04 & 02 & $50 \%$ & 0.53 \\
\hline Shock & 03 & 00 & 00 & 0.21 \\
\hline $\mathrm{IVH}^{*}$ & 03 & 00 & 00 & 0.21 \\
\hline BPD* & 02 & 02 & $100 \%$ & 0.15 \\
\hline DIC* & 02 & 00 & 00 & 0.35 \\
\hline ALS* & 01 & 00 & 00 & 0.60 \\
\hline Pulmonary hemorrhage & 01 & 00 & 00 & 0.60 \\
\hline
\end{tabular}

*VAP: Ventilator associated pneumonia; PPHN: Persistent pulmonary hypertension; IVH: Intraventricular hemorrhage; BPD: Broncho-pulmonary dysplasia; DIC: Disseminated intravascular coagulation; ALS: Air leak syndrome

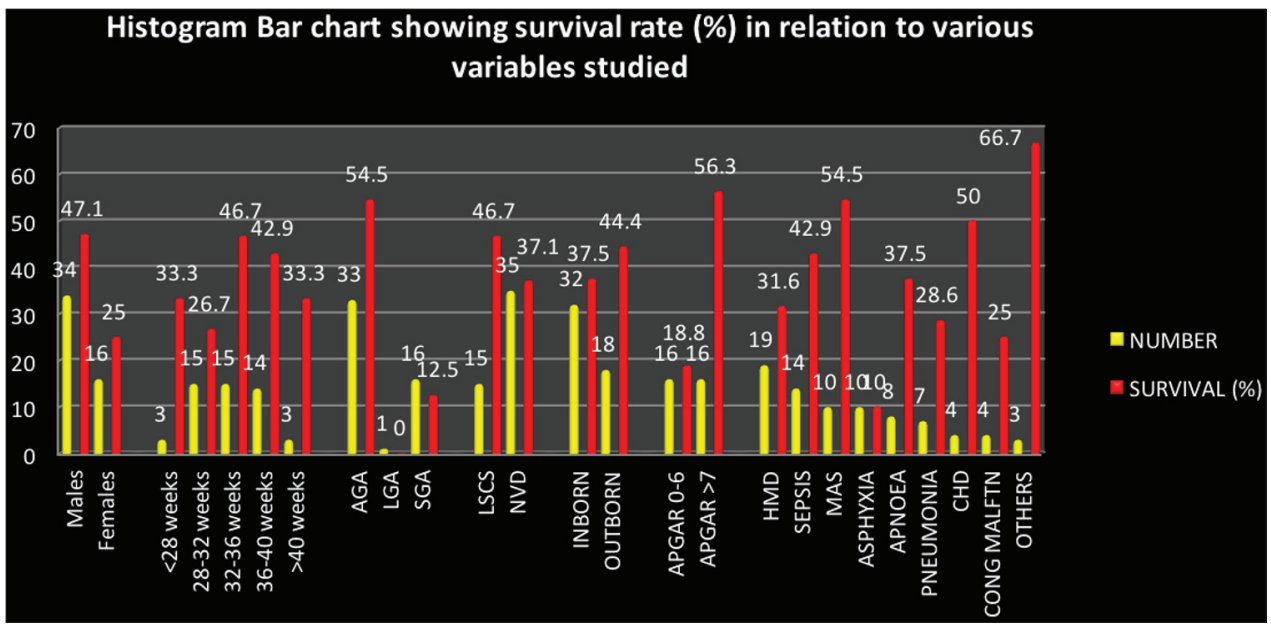

Figure 1: survival rate in relation to various study variables 
survival rate in HMD OF 53\% (Dutt et al) and 52\% (Mathur et al) respectively. The mean gestational age in the present study of survived neonates was $34.6 \pm 3.38$ weeks and in expired neonates was $33.4 \pm 4.5$ weeks. It was a statistically significant factor highlighting that survival rates is directly proportional to the gestational age. Nayana et al..$^{[4]}$ featured same in their study; survived neonates were of mean gestational age $34.5 \pm 3.5$ weeks while Hossain et al.$^{[5]}$ had babies of gestational age $33.1 \pm 4.2$ weeks having a better survival than of $36.4 \pm 2.7$ weeks. The birth weight and gender of the neonates also showed the difference in survival rate but could not be statistically justified in the present study. Males were found to have a better survival (47\%) than females (25\%). A similar trend was observed by Anantharaj and Bhat. ${ }^{[6]}$ In the present study, the most ventilated babies were of 1000-1499 $\mathrm{g}(18 \%)$ while the mean birth weight in survived neonates was $2173 \pm 665 \mathrm{~g}$ and expired neonates was $1611 \pm 792 \mathrm{~g}$. Trivedi et al., ${ }^{[7]}$ Hossain et al.,${ }^{[5]}$ and Dutt et al. ${ }^{[2]}$ also reported higher survival in babies weighing $>2000 \mathrm{~g}$ : $56.7 \%, 52.1 \%$, and $51 \%$, respectively, as in our study, it was $52.6 \%$. The intrauterine growth showed statistical significance $(P<0.01)$ showing that AGA babies had the highest survival rate $(54.5 \%)$ and mortality was least in LGA babies. Parameters such as place and mode of delivery, showed no statistical significance to highlight.

Arafa and Alshehri. ${ }^{[8]}$ in their study found a 5 min APGAR score $<7$ to be significantly associated with mortality. In our series, a similar finding was seen, that mortality was more $\mathrm{n}$ babies with APGAR score $0-6(81.2 \%)$ as compared to $>7(43.7 \%)$.

The third-most common indication for ventilation in our series, meconium aspiration syndrome (MAS), had the $2^{\text {nd }}$ best outcome with a survival of $54.5 \%$. Malhotra et al. ${ }^{[9]}$ showed MAS had the best outcome, $100 \%$ and $63 \%$, respectively, while Singh et al. ${ }^{[10]}$ have the poorest outcome where all babies in their series who were ventilated for MAS, expired. The severely asphyxiated babies (APGAR 0-3 at $5 \mathrm{~min}$ ) has the poorest survival of $10 \%(P=0.03)$. Similar to Trivedi et al., ${ }^{[7]}$ (20\%) whereas higher survival rate seen by Dutt et al., ${ }^{[2]}(40 \%)$ and Nayana et al., ${ }^{[4]}(100 \%)$.

Among all the complications, babies who landed up in shock, suffered with pulmonary hemorrhage, had air leak syndrome and IVH had $100 \%$ mortality. Sepsis was found to be the most common complication followed by VAP and P9PHN, but survival rate was best in VAP $(75 \%)$ followed by sepsis (60\%) and PPHN (50\%). Higher mortality rate with sepsis may be associated with other factors such as temperature instability, shock, dyselectrolytemia, and acidosis. Krishnan et al. $(19 \%)^{[11]}$ noted low survival rate in sepsis. Our study showed babies with BPD as complication of ventilation having $100 \%$ survival; this defines the prolonged ventilation with subsequent careful weaning off and pharmacological support.

Mechanical ventilation has effective role in reducing mortality in critically sick children, $40 \%$ survival rate found in our study. HMD was the common etiological factor for ventilation while sepsis being the most common complication of same. Increasing gestational age, appropriate intrauterine growth pattern and increasing hospital stay were associated with better outcome whereas low-APGAR score was associated with higher mortality.

\section{Financial support and sponsorship}

Nil.

\section{Conflicts of interest}

There are no conflicts of interest.

\section{RefEREnCES}

1. Downes JJ, Vidyasagar D, Boggs TR Jr., Morrow GM $3^{\text {rd }}$. Respiratory distress syndrome of newborn infants. I. New clinical scoring system (RDS score) with acid - Base and blood-gas correlations. Clin Pediatr (Phila) 1970;9:325-31.

2. Dutt RD, Dutt C, Ambey R. Neonatal mechanical ventilation-early experiences in central India. Int J Med Res Rev 2014;2:319-23.

3. Mathur NB, Garg P, Mishra TK. Predictors of fatality in neonates requiring mechanical ventilation. Indian Pediatr 2005;42:645-51.

4. Nayana PC, George RT, Francis F. Profile and outcome of neonates requiring ventilation: The Kerala experience. Curr Pediatr Res 2014;18:39-45.

5. Hossain MM, Mahfuza S, Mohammad AM, Hasan NA, Sahidullah M. Predictors of Mortality in Ventilated Neonates in Intensive Care Unit. Bangladesh J Child Health 2009;33:77-82.

6. Anantharaj A, Bhat BV. Outcome of neonates requiring assisted ventilation. Turk J Pediatr 2011;53:547-53.

7. Trivedi SS, Chudasama RK, Srivastava A. Study of early predictors of fatality in mechanically ventilated neonates in NICU. Online J Health Allied Scs 2009:8-9.

8. Arafa MA, Alshehri MA. Predictors of neonatal mortality in the Intensive Care Unit in Abha, Saudi Arabia. Saudi Med J 2003;24:1374-6.

9. Malhotra AK, Nagpal R, Gupta RK, Chhajta DS, Arora RK. Respiratory distress in newborn: Treated with ventilation in a level II nursery. Indian Pediatr 1995;32:207-11.

10. Singh M, Deorari AK, Paul VK, Mittal M, Shanker S, Munshi U, et al. Three-year experience with neonatal ventilation from a tertiary care hospital in Delhi. Indian Pediatr 1993;30:783-9.

11. Krishnan L, Francis PP, D'Souza NA, Bhaskaranand N. Assisted ventilation in neonates: The Manipal experience. Indian J Pediatr 1994;61:379-86. 